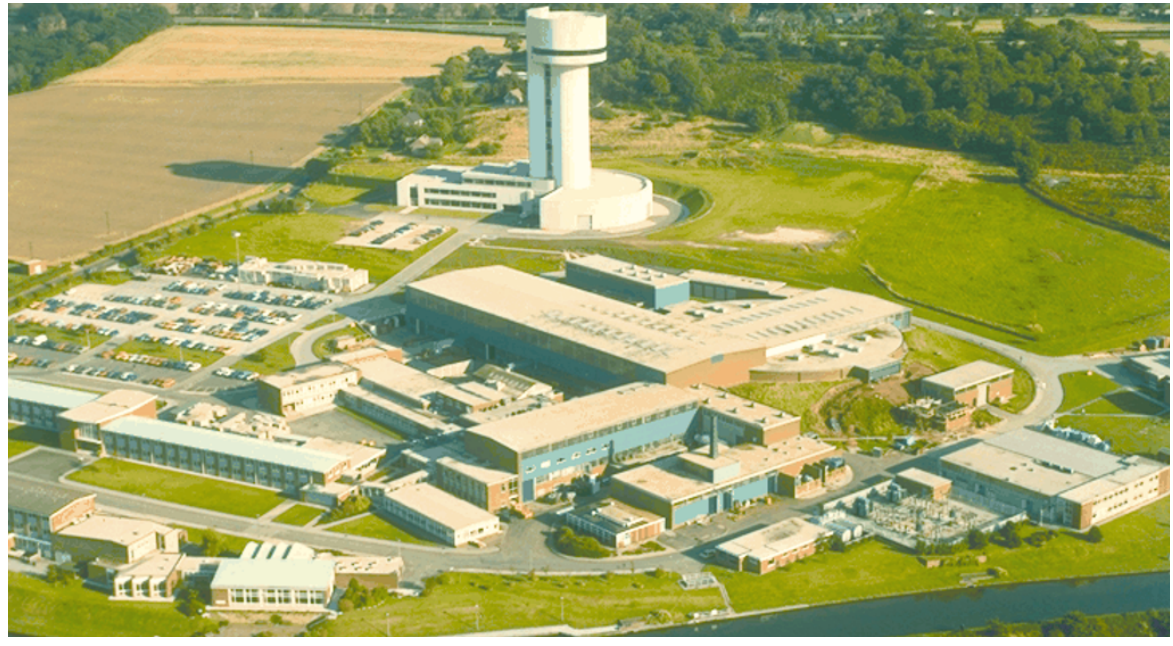

Fresh fields: the new centre 'will offer synergies in treatment, diagnosis and medicine'.

\title{
Plan for medical research base secures future of UK lab
}

\section{David Adam, London}

Scientists at the Daresbury Laboratory in northwest England are celebrating the UK government's decision to build a major new accelerator and imaging centre at the lab.

The $£ 150$ million (US\$220 million) investment should secure the laboratory's future. This had been in doubt since the government announced plans to build a synchrotron farther south at the Rutherford Appleton Laboratory in Oxfordshire (see

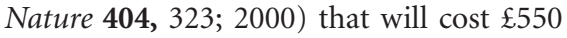
million to build and run.

Announcing the funding during a visit to Daresbury last week, the trade and industry secretary Stephen Byers said the project would "greatly enhance the northwest's science base, bring developments in the treatment of cancer and improve treatments for other diseases".

"Daresbury has an international reputation for its scientific work," Byers continued, "and is rightly a source of pride both for the region and for the country as a whole."

The new Centre for Accelerator Science, Imaging and Medicine (CASIM) will feature a proton cyclotron - which is used in various research disciplines and in cancer treatment - together with an ion-beam facility for nuclear physics, two free-electron lasers and X-ray imaging equipment. Construction work on the projects, which are still subject to scientific review and feasibility studies, could begin as early as this autumn.

The centre will work in partnership with universities, hospitals and private companies in the region. "It offers clear synergies in treatment, diagnosis and medicine," explains Peter Weightman, a surface scientist at Liverpool University who led the project proposal. Weightman says it will allow cancer treatments based on X-ray therapy and proton therapy, for example, to be compared for the first time.

Weightman believes that this linking of the science base and the country's health service was key to the proposal's success. The government can dip into both the healthservice and core-science funding pots for the money, he says, as well as using cash allocated to the regional development agency. But he insists it should not be seen as regional aid, as the new centre will be of both national and international scientific significance.

Meanwhile, Daresbury researchers are "delighted with the news", says spokesman Tony Buckley. "The staff cheered the secretary of state off the site," he says, adding that workers at the laboratory are determined to make the project a "real scientific success". Some had feared that Daresbury would close when its existing synchrotron radiation source closes in 2007, and many researchers have already left to take up jobs elsewhere.

Byers also announced that a $£ 24$ million biopharmaceutical manufacturing facility will be built in the region. It is designed to plug a gap between research and its commercial exploitation by making large numbers of candidate molecules available for earlystage trials.

And, still smarting from last year's synchrotron defeat at the hands of its Oxfordshire rival, the northwest is to get its own 'science council', adding the weight of universities and industry to the lobbying power of its existing regional development agency.

"Not often are scientists lost for words in reaction to a government announcement of funding," Weightman says. "But this morning I think we all were."

\section{Crystal chains invoked as evidence for life on Mars}

Tony Reichhardt

More than four years after researchers at the US space agency NASA reported signs of fossil life in a martian rock, another team has produced what may be the strongest evidence yet to support the controversial finding. But many scientists are still unconvinced by the claims.

Microbiologist Imre Friedmann, an emeritus professor at Florida State University and a specialist on life in extreme environments, says that highpower electron-microscope images of magnetite crystals in the meteorite suggest that they are of biological origin.

Writing in Proceedings of the National Academy of Sciences (98, 2176-2181; 2001), Friedmann and his colleagues describe chains of magnetite, which some terrestrial bacteria use to orientate themselves in Earth's magnetic field. They say the chains are too orderly to have been produced without the action of living organisms. The images also reveal possible remnants of membranes around the crystals, which are of uniform size and shape.

Meanwhile, Kathie Thomas-Keprta, a planetary scientist at NASA's Johnson Space Center in Houston, Texas, and coauthor of the original paper on fossils in the meteorite, has examined individual magnetite grains. Some $25 \%$ of the magnetites in the meteorite show characteristics of crystals produced by living organisms, she and her colleagues write in the same issue of the journal.

But most experts remain sceptical. Allan Treiman, a researcher at the Lunar and Planetary Institute in Houston, will claim in a talk next week at the institute's annual science conference that the grains were created by ordinary decomposition of iron-rich carbonate minerals.

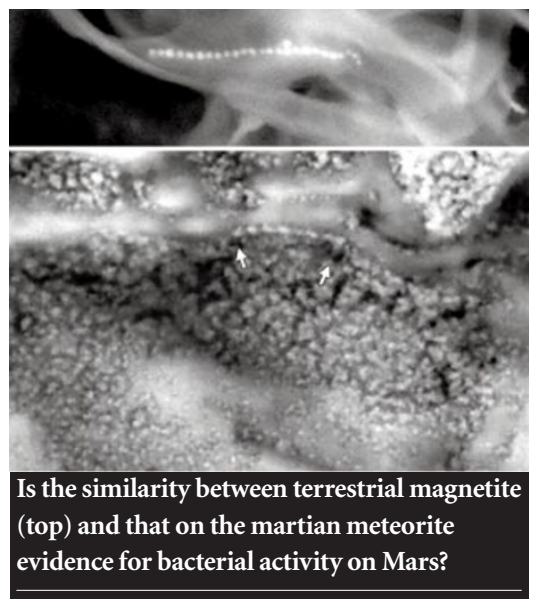

